\title{
Optimasi Portofolio Saham Lq 45 Di Era Pandemi Covid 19
}

\author{
Aisha Hanif ${ }^{1}$, Nur Ravita Hanun ${ }^{2}$, Rizky Eka Febriansah ${ }^{3}$ \\ Fakultas Bisnis, Hukum dan IImu Sosial Universitas Muhammadiyah Sidoarjo ${ }^{123}$ \\ email korespondensi: aishahanif@umsida.ac.id
}

\begin{abstract}
Abstrak: Pasar modal Indonesia menjadi alternatif investasi yang menarik di tengah peningkatan akses informasi dan teknologi seperti saat ini. Berbagai instrumen investasi hadir ditengah masyarakat, salah satunyanya adalah instrumen saham. Saham merupakan salah satu instrumen investasi populer yang diperjual belikan di pasar modal. Kepopuleran saham terjadi seiring dengan masifnya gerakan literasi keuangan untuk membeli saham terutama di kalangan anak muda dan generasi millennial. Namun, masifnya gerakan ini harus diimbangi dengan pengetahuan serta keahlian dalam mengelola instrumen saham. Salah satu caranya dengan membentuk portofolio saham optimal yang mengoptimalkan keuntungan yang didapat namun meminimalkan risiko yang akan dihadapi melalui diversifikasi dan mengkombinasikan berbagai instrumen investasi kedalam portofolio.Tujuan dari penelitian ini adalah untuk mengetahui sahamsaham mana sajakah yang dapat membentuk suatu portofolio optimal terutama di era pandemi Covid 19 dan untuk mengetahui proporsi yang optimal dari portofolio setiap saham yang layak untuk memperoleh portofolio optimal pada saham Indeks LQ 45. Sampel penelitian ini menggunakan saham-saham yang terdaftar dalam Indeks LQ 45 dan pemilihan saham adalah saham yang memiliki rata-rata return positif. Hasil dari penelitian ini adalah didapatkan portofolio optimal yang terdiri dari saham KLBF $(52,22 \%)$, ERAA $(11,69 \%)$, ANTM $(11,29 \%)$, JSMR $(8,98 \%)$, INCO $(5,19 \%)$, BBCA $(6,58 \%), \operatorname{EXCL}(2,55 \%), \operatorname{MNCN}(1,27 \%), \operatorname{BRPT}(0,23 \%)$.
\end{abstract}

Kata kunci: Optimasi, Portofolio, Saham, Investasi

Tandelilin (2010) menjelaskan investasi ini dilakukan karena akan mendatangkan hasil yang berupa return, yang merupakan salah satu faktor yang memotivasi investor untuk bervinvetasi dan sebagai imbalan atas keberanian investor dalam menghadapi risiko yang ditanggungnya. Investasi dapat dilakukan dalam berbagai jenis aset, yaitu aset riil dan aset keuangan. Investasi pada aset keuangan memiliki keunggulan karena sifatnya lebih likuid yang berarti, tidak membutuhkan waktu yang lama untuk membuat suatu investasi keuangan menjadi kas. Sifat likuid ini diperoleh karena fluktuasi nilai aset keuangan cukup tajam karena, dalam jangka waktu yang singkat nilai aset tersebut dapat berubah-ubah yang membuat para investor tertarik dengan aset tersebut (Tandelilin, 2010).

Dalam melakukan investasi, seorang investor tidak mengetahui dengan pasti hasil yang akan diperoleh dari investasi yang dilakukan. Tujuan investor melakukan investasi adalah untuk memaksimalkan return yang akan didapat, namun selain return investor juga juga akan menghadapi risiko investasi. Risiko investasi yaitu investor yang gagal mendapatkan kembali modalnya dikarenakan emiten saham dinyatakan pailit atau sahamnya tidak laku diperjualbelikan atau sudah dikeluarkan dari pencatatan di Bursa Efek (Samsul, 2015). Untuk meminimalkan risiko, investor dapat melakukan diversifikasi yakni membentuk portofolio yang 
optimal, hal ini dilakukan untuk meminimalkan risiko yang tidak dapat dihilangkan. Portofolio dapat dikatakan efisien dibandingkan portofolio lain apabila memberikan imbal hasil terbesar yang diharapakan dengan risiko yang sama, atau memberikan risiko terkecil dengan imbal hasil yang diharapkan sama (Halim 2015). Pada tahun 1952, Markowitz membuat model seleksi portofolio yang memasukkan prinsip diversifikasi. Penentuan portofolio optimal tersebut dikenal sebagai penentuan portofolio optimal model Markowitz (Elton et al.2014). Portofolio optimal dengan Model Markowitz yang dipilih dari berbagai alternatif dari portofolio efisien, dapat memberikan return tertentu sesuai dengan risiko yang berani dihadapi oleh investor (Ticoh, 2010). Salah satu kelebihan Model Markowitz adalah portofolio mudah terbentuk agar disesuaikan dengan ciri-ciri investasi dan tujuan yang diinginkan (Natalia dkk. 2012). Selanjutnya, William Sharpe mengembangkan model yang dikenal dengan Model Indeks Tunggal untuk menyederhanakan perhitungan model Markowitz. Model Indeks Tunggal didasarkan pada pengamatan bahwa harga dari suatu sekuritas berfluktuasi searah dengan indeks harga pasar (Cornuejols dan Tutuncu 2007). Model analisis pembentukan portofolio sangat membantu investor dalam menanamkan modalnya agar memperoleh kombinasi keuntungan dan risiko terbaik. Anggraeni dan Mispiyanti (2020) menyebutkan bahwa model indeks tunggal dapat memberikan gambaran kepada investor untuk dapat dijadikan acuan dalam berinvestasi.

Di sisi lain, tidak bisa dipungkiri bahwa terdapat berbagai risiko yang tidak terduga dalam berinvestasi, salah satunya adalah pandemi Covid 19 yang sedang melanda dunia. Sampai dengan tanggal 12 Oktober 2020, Indonesia telah melaporkan 370.000 kasus positif Covid19. Dampak dari COVID-19 yang melanda berbagai belahan negara khususnya Indonesia, sangat berdampak terhadap terhadap perekonomian, tidak terkecuali dalam investasi saham. Dewi dan Masithoh (2020) menyebutkan bahwa hasil IHSG megalami beda signifikan, yaitu tren menurun tajam pada waktu saat terjadinya pandemi COVID-19 dibandingkan sebelum pandemi. Pada penelitian-penelitian sebelumnya belum pernah dibahas tentang pembentukan portofolio optimal pada masa pandemik Covid 19, sehingga penelitian ini akan membahas terkait dengan optimasi investasi saham LQ 45 di era pandemi Covid 19.

\section{METODE}

Dalam penelitian ini data populasi yang digunakan adalah seluruh perusahaan yang masuk dalam Liquid-45 (LQ-45) yang terdaftar di Bursa Efek Indonesia (BEI) periode 2019-2020. Perusahaan yang menjadi sampel dalam penelitian ini dipilih dengan menggunakan metode purposive sampling, dimana sampel yang dipilih berdasarkan karakteristik tertentu atau pertimbangan tertentu oleh peneliti. Kriteria pemilihan sampel saham LQ-45 adalah tidak terkena auto-reject diatas 1 (satu) kali 
selama periode 2019-2020. Berdasarkan populasi sebanyak 45 perusahaan yaitu perusahaan yang termasuk dalam indeks LQ45 pada PT Bursa Efek Indonesia, terdapat 39 perusahaan dari populasi tersebut yang memenuhi kriteria untuk dijadikan sampel penelitian dan hanya terdapat 6 perusahaan yang tidak masuk dalam indeks LQ45 secara berturut-turut. Metode pengumpulan data yang digunakan dalam penelitian ini menggunakan metode observasi non partisipan. Teknik analisis data dalam penelitian ini menggunakan single indeks model sebagai metode pembentukan portofolio yang optimal.

\section{HASIL}

Langkah pertama dalam pembentukan portofolio optimal dengan menggunakan single indeks model adalah menghitung return masingmasing saham (Rit), expected return masing-masing saham ( $E(R i)$ ), deviasi standar masing-masing saham $(\sigma \mathrm{i})$, dan varian masing-masing saham $\left(\sigma \mathrm{i}^{2}\right)$. Dari 39 saham perusahaan yang menjadi sampel penelitian, yang memiliki realisasi return tertinggi adalah emiten BRPT sebesar 1,2864 dan realisasi return terendah adalah emiten LPPF dengan nilai sebesar -0,9119. Untuk perhitungan expected return terdapat 11 emiten yang memiliki expected return positif, yaitu ADRO, ANTM, BBCA, BRPT, ERAA, EXCL, INCO, JSMR, KLBF, MNCN, WIKA dengan nilai terbesar adalah 0,0677 .

Langkah selanjutnya dalam pembentukan portofolio optimal adalah menghitung standar deviasi dan varians masing-masing saham yang menjadi sampel penelitian. Semakin besar nilai varians, maka semakin jauh perbedaan antara actual return dan average return. Simpangan baku atau standar deviasi adalah akar kuadrat dari varians. Nilai standar deviasi tertinggi dari 39 saham yang menjadi sampel penelitian adalah emiten BRPT dengan nilai sebesar 0,6094 dengan nilai varians sebesar 0,0797, dan saham dengan nilai standar deviasi terendah adalah emiten ADRO sebesar 0,0088 dengan nilai varians sebesar 0.0142 .

Langkah kedua dalam pembentukan portofolio optimal adalah menghitung market return $(\mathrm{Rm})$ market expected return $(\mathrm{E}(\mathrm{Rm}))$, deviasi standar pasar $(\sigma \mathrm{i})$, dan varians pasar $\left(\sigma \mathrm{i}^{2}\right)$ dengan menggunakan data historis bulanan Indeks Harga Saham Gabungan (IHSG) sebagai indeks pasar. Nilai market return dengan menggunakan data historis nilai IHSG bulanan adalah sebesar -0,1564 dengan market expected return sebesar 0,0082, kemudian deviasi standar pasar adalah sebesar 0,0520 dengan varian pasar sebesar 0,0027 .

Langkah ketiga dalam pembentukan portofolio optimal adalah menghitung Beta $(\beta i)$ dan Alpha ( $\alpha i)$ masing-masing saham yang menjadi sampel penelitian. Semakin besar beta, maka akan semakin besar pula sensitivitas sekuritas untuk kembali ke pasar. Alpha merupakan komponen pengembalian yang terkait dengan keunikan suatu perusahaan. Nilai beta tertinggi yang terdapat dalam sampel penelitian ini adalah pada emiten PTPP 3,4448 sedangkan nilai beta terendah adalah 
pada emiten ICBP sebesar 0,1869. Sedangkan untuk saham dengan nilai alpha tertinggi adalah emiten ANTM sebesar 0,0844 dan saham dengan nilai alpha terendah adalah emiten GGRM dengan nilai sebesar -0,0321.

Langkah keempat dalam pembentukan portofolio optimal adalah menghitung residual error variance masing-masing saham yang menjadi sampel penelitian. Dari 39 saham yang menjadi sampel penelitian didapatkan hasil bahwa saham dengan residual error variance tertinggi adalah emiten BRPT dengan nilai sebesar 0,0844 dan saham dengan residual error variance terendah adalah emiten WIKA dengan nilai sebesar 0,0226.

Langkah kelima dalam pembentukan portofolio optimal adalah menghitung Excess Return to Beta (ERB) masing-masing saham yang menjadi sampel penelitian. Terdapat 9 saham yang memiliki ERB positif, saham-saham tersebut adalah emiten KLBF, ERAA, ANTM, JSMR, INCO, BBCA, EXCL, MNCN, BRPT dan terdapat 30 saham yang memiliki ERB negatif. Saham dengan nilai Excess Return to Beta (ERB) tertinggi adalah emiten KLBF dengan nilai sebesar 1632,28.

Langkah keenam dalam pembentukan portofolio optimal adalah menghitung $\mathrm{Ci}$ (Cut of Rate) kemudian menentukan titik potong $\left(\mathrm{C}^{*}\right)$. Perhitungan titik potong $\left(C^{*}\right)$ adalah sebesar 0,0034 . Artinya nilai 0,0034 digunakan sebagai titik pembatas untuk menentukan saham mana yang menjadi kandidat portofolio optimal dengan membandingkan nilai ERB masing-masing saham (ERB> 0,0034), jika nilai ERB saham tersebut lebih besar dari pada titik pembatas. sebesar 0,0035, maka saham termasuk dalam kandidat portofolio optimal. Saham-saham yang termasuk dalam portofolio optimal adalah emiten KLBF, ERAA, ANTM, JSMR, INCO, BBCA, EXCL, MNCN, BRPT.

Langkah ketujuh dalam pembentukan portofolio optimal adalah menghitung proporsi dana masing-masing emiten yang termasuk dalam kandidat portofolio optimal. Proporsi dana tertinggi dari portofolio saham optimal adalah emiten KLBF dengan proporsi $52,22 \%$, sedangkan proporsi dana terendah dari portofolio saham optimal adalah emiten BRPT dengan proporsi 0,23\%. Untuk proporsi emiten-emiten lainnya adalah ERAA (11,69\%), ANTM (11,29\%), JSMR (8,98\%), INCO (5,19\%), BBCA (6,58\%), EXCL (2,55\%), MNCN (1,27\%).

Langkah kedelapan dalam pembentukan portofolio optimal dengan menggunakan single indeks model adalah menghitung expected return portofolio dan risiko portofolio. Nilai expected return portofolio adalah sebesar 0,0074 dan nilai risiko portofolio adalah sebesar 0,0027. Hal ini menunjukkan bahwa expected return portofolio adalah sebesar $0,74 \%$ dengan tingkat risiko portofolio sebesar 0,27\%.

Berdasarkan hasil perhitungan di atas, diketahui bahwa dari 39 saham LQ 45 yang merupakan sampel dalam penelitian ini didapatkan hasil yaitu terdapat 9 saham yang masuk menjadi saham-saham pembentuk portofolio optimal dalam rentang periode 2019-2020 dengan menggunakan single index model. Saham-saham tersebut diantaranya 
adalah ERAA (11,69\%), ANTM (11,29\%), JSMR (8,98\%), INCO (5,19\%), BBCA (6,58\%), EXCL (2,55\%), MNCN (1,27\%).

Hasil penelitian ini memberikan implikasi teoritis yang menyatakan bahwa saham-saham yang termasuk dalam indeks LQ45 dapat digunakan untuk membentuk sebuah portofolio yang optimal dengan menggunakan single index model. Portofolio yang dibentuk dengan diversifikasi terbukti membantu mengurangi tingkat risiko investasi. Hasil ini juga menunjukkan bahwa portofolio yang dibentuk dengan menggunakan single index model sesuai dengan teori portofolio single index model yang menyebutkan bahwa harga suatu saham berfluktuasi searah dengan indeks harga pasar. Hasil penelitian ini sejalan dengan penelitian sebelumnya dari Putra (2020) dan Chasanah (2020).

\section{KESIMPULAN}

Pembentukan portofolio optimal dengan menggunakan metode single index model menunjukkan bahwa terdapat 9 saham yang menjadi penyusun portofolio optimal yaitu saham KLBF, ERAA, ANTM, JSMR, INCO, BBCA, EXCL, MNCN, BRPT. Proporsi dari 9 saham tersebut adalah ERAA (11,69\%), ANTM (11,29\%), JSMR $(8,98 \%)$, INCO (5,19\%), BBCA (6,58\%), EXCL (2,55\%), MNCN (1,27\%). Evaluasi kinerja portofolio optimal dengan menggunakan parameter single index model menunjukkan bahwa pembentukan portofolio optimal memberikan kinerja terbaik dengan nilai parameter kinerja yaitu dengan nilai expected return portofolio adalah sebesar 0,0074 dan nilai risiko portofolio adalah sebesar 0,0027 . Hal ini menunjukkan bahwa expected return portofolio adalah sebesar $0,74 \%$ dengan tingkat risiko portofolio sebesar $0,27 \%$. Investor dengan tipe konservatif yang memiliki kecenderungan untuk menghindari resiko (risk averse) dapat menginvestasikan dananya pada portofolio saham optimal yang dibentuk dengan menggunakan single indeks model karena tingkat risiko yang diberikan lebih rendah. Untuk penelitian selanjutnya dapat lebih fokus pada objek penelitian yang meliputi perusahaan dengan sektor yang sama karena dapat membandingkan perusahaan secara komprehensif di dalam satu sektor. Selain itu penelitian selanjutnya juga diharapkan dapat menggunakan berbagai alat analisis yang menggunakan konsep risiko dengan menggunakan rentang waktu yang lebih lama.

\section{DAFTAR PUSTAKA}

Anggraeni RW, \& Mispiyanti. 2020. Analisis pembentukan portofolio optimal saham dengan menggunakan model indeks tunggal (Studi kasus pada perusahaan terdaftar di indeks SRI-KEHATI periode 2016-2018). Jurnal IImiah Mahasiswa Manajemen, Bisnis dan Akuntansi. Volume 2, No. 1.

Chasanah, S. I. U., Abdullah, S., Valentika, N., Kiftiyani, U., \& Nuha, A. R. (2020). ANALISIS PEMBENTUKAN PORTOFOLIO OPTIMAL SAHAM-SAHAM JAKARTA ISLAMIC INDEX (JII) PADA MASA 
PANDEMI COVID-19. Jurnal Saintika Unpam: Jurnal Sains dan Matematika Unpam, 3(1), 52-67.

Cornuejols G, \& Tutuncu R. 2007. Optimization Method in Finance. New York (US): Cambridge Univ Pr.

Dewi CK, \&. M. (2020). IHSG and trading activities before after covid-19 outbreak. Research Journal of Accounting and Business Management (RJABM), 2580-3131.

Elton, E. J. (2014). Modern Portfolio Theory and Investment Analysis. New York: Jhon Wiley Son.

Fahmi, I. (2013). Pengantar Pasar Modal. Bandung: Alfabeta.

Gurrib, I. a. (2012). Diversification in Portfolio Risk Management: The Case of UAE Financial Market. International Journal of Trade, Economics and Finance, 445-449.

Halim, A. (2015). Analisis Investasi dan Aplikasinya: Dalam Aset Keuangan. Jakarta: Salemba Empat.

Hartono, J. (2014). Teori Portofolio dan Analisis Investasi. Yogyakarta: BPFE.

Husnan, S. (2009). Dasar-Dasar Teori Portofolio dan Analisis Sekuritas. Yogyakarta: Sekolah Tinggi Ilmu Manajemen YKPN.

Natalia, E. D. (2014). Penentuan Portofolio Saham yang Optimal Dengan Model Markowitz Sebagai Dasar Penetapan Investasi Saham (Studi pada Perusahaan Food and Beverage yang Terdaftar di Bursa Efek Indonesia Tahun 2012). Jurnal Administrasi Bisnis, 9.

Putra, I. K. A. A. S., \& Dana, I. M. (2020). Study of Optimal Portfolio Performance Comparison: Single Index Model and Markowitz Model on LQ45 Stocks in Indonesia Stock Exchange.

Samsul, M. (2015). Pasar Modal dan Management Portofolio. Surabaya: Erlangga.

Sunariyah. (2006). Pengantar Pengetahuan Pasar Modal. Yogyakarta: UPP AMP YKPN.

Tandelilin, E. (2010). Portofolio dan Investasi. Yogyakarta: Kanisius.

Ticoh, J. D. (2010). Optimalisasi Portofolio Proyek Dengan Menggunakan. Jurnal Pendidikan Teknologi dan Kejuruan, 204-215.

Zalmi, Z. (2011). Manajemen Portofolio: Penerapannya Dalam Investasi. Jakarta: Salemba Empat. 